Revista Brasil. Bot., V.31, n.3, p.409-424, jul.-set. 2008

\title{
Flora fanerogâmica não-arbórea do cerrado na Estação Ecológica de Assis, Estado de São Paulo
}

\author{
DAVI RODRIGO ROSSATTO ${ }^{1,4}$, MARIA TERESA ZUGLIANI TONIATO² e GISELDA DURIGAN ${ }^{3}$
}

(recebido: 23 de novembro de 2006; aceito: 12 de junho de 2008)

\begin{abstract}
Non-arboreal phanerogamic cerrado flora of Assis Ecological Station, state of São Paulo). The cerrado vegetation in São Paulo State is restricted to a few remnants which non-arboreal flora has rarely been studied. The present study aimed at characterizing the non-arboreal phanerogamic flora occurring in distinct "cerrado" vegetation types (wet camp, cerrado sensu stricto, woodland cerrado and riparian forest) at Assis Ecological Station $\left(22^{\circ} 33^{\prime} 65^{\prime \prime}\right.$ to $22^{\circ} 36$ ' $68^{\prime \prime}$ S and $50^{\circ} 22^{\prime} 29^{\prime \prime}$ to $50^{\circ} 23^{\prime} 00^{\prime \prime}$ W), Assis municipality, São Paulo State, Brazil, and, by comparison with other "cerrado" sites in the state, verifying possible occurrence of endemic or rare species. A floristic survey was carried out and a total of 301 species, 199 genera and 61 families of non-arboreal phanerogamic plants were found. The richest families for the studied life forms in the area were: Fabaceae, Asteraceae, Bignoniaceae and Poaceae. Richness in the physiognomies, in decreasing order, was 146 species in the cerrado sensu stricto (48.8\%), 48 species in the woodland cerrado (15.9\%), 47 in the wet camp (15.6\%), and, at last, the riparian forest, with 15 species (5.0\%). Compared to other cerrado areas, the diversity of the local non-arboreal flora is high. There is, also, a high number of species (102 or 34\%) exclusive from the studied area. High proportions of non-arboreal species occurring in a single locality have been also observed in other studies, indicating that either endemism can be higher among these life-forms than among arboreal species or inventory methods were not adequate to survey the total richness of the studied areas. Conservation strategies and botanical inventories must especially consider the non-arboreal flora, since arboreal species are both more widespread and proportionally better known.
\end{abstract}

Key words - cerrado vegetation, conservation, diversity, floristic inventory

RESUMO - (Flora fanerogâmica não-arbórea do cerrado na Estação Ecológica de Assis, Estado de São Paulo). A vegetação de cerrado no Estado de São Paulo sobrevive em poucas áreas naturais remanescentes cuja flora, exceto pelas espécies arbóreas, é pouco conhecida. O presente estudo teve como objetivo caracterizar a flora fanerogâmica não-arbórea das diferentes fisionomias da vegetação (campo úmido, cerrado sensu stricto, cerradão e mata ciliar) na Estação Ecológica de Assis

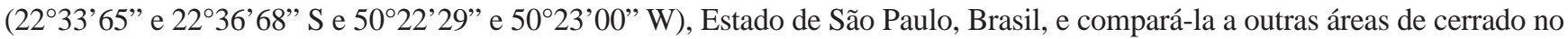
estado, para verificar possíveis endemismos ou a presença de espécies raras, que mereçam providências especiais de manejo para sua conservação. Nas diferentes fisionomias da vegetação no interior da unidade de conservação foram registradas 301 espécies fanerógamas não-arbóreas, pertencentes a 199 gêneros e 61 famílias. As famílias com os maiores números de espécies foram: Fabaceae, Asteraceae, Bignoniaceae e Poaceae. A riqueza de espécies foi decrescente do cerrado sensu stricto (146 espécies ou 48,8\%), seguido pelo cerradão (48 espécies ou 15,9\%), campo úmido (47 espécies ou 15,6\%) e, por último, a mata ciliar (15 espécies ou 5,0\%). Comparada às outras áreas analisadas de cerrado no Estado de São Paulo, a diversidade da flora não-arbórea local é elevada. O alto nível de ocorrências únicas para as formas de vida inventariadas (102 espécies ou 34\%) tem sido igualmente observado em outros estudos, indicando que ou os endemismos são mais comuns para espécies vegetais não-arbóreas do que para arbóreas ou os métodos de inventário não têm sido adequados para representar toda a riqueza dessas espécies em cada local. Estratégias de conservação e inventários botânicos devem valorizar especialmente a flora não-arbórea, uma vez que as espécies da flora arbórea apresentam-se mais amplamente distribuídas e melhor inventariadas.

Palavras-chave - conservação, diversidade, flora do cerrado, inventário florístico

\section{Introdução}

A vegetação de cerrado cobria, originalmente, cerca de $23 \%$ do território brasileiro, apresentando uma área

1. Universidade de Brasília, Instituto de Ciências Biológicas, Departamento de Botânica, Laboratório de Fisiologia Vegetal, Instituto Central de Ciências Módulo 01, Caixa Postal 04457, 70904-970 Brasília, DF, Brasil.

2. Instituto Florestal, Estação Experimental de Bauru, Avenida Rodrigues Alves, 38-25 - Horto Florestal, 17030-000 Bauru, SP, Brasil.

3. Instituto Florestal, Floresta Estadual de Assis, Estrada Vicinal AssisLutécia km 9. Caixa Postal 104, 19802-970 Assis, SP, Brasil.

4. Autor para correspondência: drrossatto@gmail.com core nos estados da região Centro-Oeste e regiões disjuntas nos estados do Sudeste e Nordeste (Ratter et al. 1997). Estima-se que no estado de São Paulo o bioma Cerrado ocupava originalmente cerca de 1.837 .150 ha em 1962, sendo reduzido a apenas 211.925 ha em 2000-2001 (São Paulo 2005), o que representa uma perda de $88 \%$ de sua área em quatro décadas. Menos de $10 \%$ da área total remanescente do Cerrado está protegida na forma de Unidades de Conservação estaduais, incluindo as Áreas de Proteção Ambiental (APAs). Além dessas áreas, alguns fragmentos estão legalmente amparados por serem categorizados como Áreas de Preservação Permanente 
(APPs) ou por se enquadrarem nos $20 \%$ de Reserva Legal obrigatória, estabelecidos pela lei 7.803/89, a serem preservados em todas as propriedades rurais (São Paulo 1997).

O levantamento florístico é um dos estudos iniciais para o conhecimento da vegetação de determinado local, fornecendo informações importantes para a compreensão dos padrões de distribuição geográfica das espécies, para a verificação de possíveis endemismos e para acrescentar conhecimentos que podem subsidiar a determinação de áreas prioritárias para a conservação (Felfili \& SilvaJunior 1993, Mendonça et al. 1998). Compilações a respeito da flora do Cerrado de todo o Brasil, realizadas no final da década de 1990, mostraram uma riqueza em torno de 5.000 espécies de plantas vasculares (Mendonça et al. 1998, Castro et al. 1999). No entanto, levantamento recente, reunindo informações da literatura e de materiais depositados em herbários (Walter 2006), resultou em 11.046 espécies, mostrando que a diversidade vegetal encontrada na extensa área de domínio do Cerrado supera consideravelmente os números e as previsões anteriormente divulgados.

Encontram-se na literatura muitos estudos a respeito da flora do Cerrado das diversas regiões do Estado de São Paulo, destacando-se entre os mais recentes os trabalhos de Coral et al. (1990) em Agudos; Mantovani \& Martins (1993), em Moji Guaçu; Batalha et al. (1997), em Pirassununga; Christianini \& Cavassan (1998), em Bauru; Araújo et al. (1999), em Franca; Durigan et al. (1999), em Assis; Batalha \& Mantovani (2001) e Weiser \& Godoy (2001), em Santa Rita do Passa Quatro; Durigan et al. (2002), em Brotas; Teixeira et al. (2004) em Patrocínio Paulista e Tannus \& Assis (2004), em Itirapina.

Apesar dos diversos inventários florísticos já realizados no Cerrado, autores como Mendonça et al. (1998) e Felfili et al. (2004) consideram insuficiente o conhecimento florístico existente, devido à grande diversidade vegetal do cerrado, ao predomínio de estudos realizados com a forma de vida arbórea, e ao grande número de tipos fisionômicos e variações de tipos de solo e relevo dentro da área de domínio do Cerrado. Assim, estima-se que especialmente a riqueza da flora herbáceo-arbustiva dos cerrados seja pouco conhecida, com base na escassez de estudos deste componente da comunidade vegetal (Ratter et al. 1997, Tannus \& Assis 2004). No Estado de São Paulo, apenas os levantamentos realizados por Mantovani \& Martins (1993), Christianini \& Cavassan (1998), Batalha et al. (1997), Batalha \& Mantovani (2001) e Tannus \& Assis (2004) foram dirigidos às formas de vida não-arbóreas, sendo os demais exclusivos ou priorizando a flora arbórea, tendo as outras formas de vida apenas como informação complementar.

Estudos aprofundados do componente herbáceoarbustivo são importantes, pois muitos autores têm relatado variações significativas em sua composição entre as diferentes regiões de cerrado, seja no próprio Estado de São Paulo (Tannus \& Assis 2004) ou em áreas do Brasil central (Felfili et al. 2004). A flora do Cerrado é considerada muito rica e, em vista do acelerado desaparecimento do cerrado, a ampliação do conhecimento de sua vegetação se faz urgente, frente à necessidade de priorizar áreas para a preservação e dar suporte aos trabalhos de manejo visando à conservação ou à restauração do ecossistema em áreas que tenham sido desmatadas.

O presente estudo teve como objetivo caracterizar a flora fanerogâmica não-arbórea das diferentes fisionomias da vegetação na Estação Ecológica de Assis, SP, comparando-a com outras áreas de cerrado no estado, para verificar possíveis endemismos ou a presença de espécies raras, que mereçam providências especiais de manejo para sua conservação.

\section{Material e Métodos}

Área de estudo - A Estação Ecológica de Assis está localizada no Município de Assis, região sudoeste do Estado de São Paulo, distante cerca de $12 \mathrm{~km}$ da sede do município, ocupando atualmente área de 1.760,64 ha. Localiza-se entre as coordenadas geográficas $22^{\circ} 33^{\prime} 20^{\prime \prime}$ a $22^{\circ} 37^{\prime} 41^{\prime \prime}$ de latitude Sul e $50^{\circ} 24^{\prime} 48^{\prime \prime}$ a $50^{\circ} 21^{\prime} 27^{\prime \prime}$ de longitude Oeste, entre altitudes de 500 e $588 \mathrm{~m}$, em relevo suave ondulado.

A Estação Ecológica situa-se em zona de transição entre climas Cwa e Cfa, segundo a classificação de Köppen, tipos climáticos que diferem essencialmente na duração da estação seca. Na região de estudo as chuvas são concentradas no verão e a precipitação média anual gira em torno de $1.400 \mathrm{~mm}$, com temperaturas médias ao redor de $21,8{ }^{\circ} \mathrm{C}$, podendo ocorrer geadas severas (ver Brando \& Durigan 2004). Os solos da Estação Ecológica de Assis são geralmente arenosos, ácidos e de baixa fertilidade. Juhász et al. (2006), em levantamento ultra detalhado ao longo de uma vertente no interior da unidade, encontraram os seguintes tipos de solo (classificados de acordo com Embrapa 1999): Latossolo Vermelho distrófico típico (LVd); Latossolo Vermelho-Amarelo distrófico típico (LVAd); Latossolo Amarelo distrófico típico (LAd) e Gleissolo Háplico Tb distrófico argissólico (GXbd).

Trata-se de uma das áreas mais ao sul da extensa região de domínio do Cerrado, onde a vegetação savânica forma, com a floresta estacional semidecidual, um mosaico geralmente associado às características físico-químicas dos solos. A vegetação da Estação Ecológica de Assis caracteriza-se como Cerrado sensu lato, predominando a fisionomia cerradão. Também são encontradas fisionomias florestais ripárias 
(paludícolas ou não), junto às quais se encontram pequenos trechos de campo úmido, segundo a classificação de físionomias proposta por Ribeiro \& Walter (1998). Ainda na área da Estação ocorrem manchas de vegetação com estrato arbóreo descontínuo, com fisionomia de cerrado sensu stricto e uma pequena faixa ecotonal, onde ocorrem espécies da floresta estacional semidecidual (Durigan et al. 1999).

Levantamento florístico - Foram realizadas coletas de material botânico a partir do ano de 1999, intensificadas por meio de um inventário sistemático, realizado quinzenalmente, entre setembro/2004 a janeiro/2006, tendo sido coletado somente material em estágio reprodutivo durante todo o período. Trilhas, aceiros e o interior da área de estudo foram percorridos nas expedições de coleta, buscando abranger as diferentes fisionomias da vegetação, com o objetivo de amostrar o maior número possível de espécies fanerógamas não-arbóreas em estágio reprodutivo. As espécies coletadas foram classificadas quanto à forma de vida de acordo com a classificação proposta por Durigan et al. (2004), sendo assim definidas: - arbusto: vegetal variando entre 1 a 5 metros de altura, resistente e lenhoso, sem tronco predominante, ramificando-se desde a base; $\bullet$ subarbusto: altura geralmente inferior a $1 \mathrm{~m}$, normalmente herbáceo, porém lenhoso na base do caule; • erva: planta de pequeno porte, cujo caule possui pouco ou nenhum tecido lenhoso; • trepadeira: planta herbácea ou lenhosa, com ramos longos, delgados e flexíveis ou com gavinhas, que cresce geralmente apoiada sobre plantas eretas lenhosas.

Para cada espécime coletado foram anotados porte, hábito, altura, coloração das flores e/ou frutos, características das folhas e outras informações relevantes para auxiliar na identificação. As amostras do material coletado foram herborizadas segundo os procedimentos usuais, conforme proposto por Fidalgo \& Bononi (1984). As espécies foram identificadas com auxílio de literatura especializada (Wanderley et al. 2001, 2002, 2003, 2005), auxílio de taxonomistas e comparação com material de herbários, especialmente com a Coleção Botânica da Floresta Estadual de Assis e com o acervo do Herbário D. Bento Pickel (SPSF), do Instituto Florestal de São Paulo. As exsicatas das espécies coletadas foram registradas e incorporadas aos acervos supracitados.

A listagem florística apresentada e utilizada nas análises foi extraída da flora arbustivo-arbórea local já conhecida (Durigan et al. 1999), à qual foram acrescentadas as espécies coletadas neste levantamento e não registradas anteriormente. Todas as espécies foram agrupadas nas famílias reconhecidas por The Angiosperm Phylogeny Group - APG II (2003).

Efetuaram-se cálculos de similaridade florística entre a Estação Ecológica de Assis e outras áreas de Cerrado no Estado de São Paulo (figura 1), visando a analisar a diversidade desse componente da comunidade vegetal em uma escala regional. Foram selecionados para comparação tanto os estudos direcionados especificamente para a flora não-arbórea, como outros mais abrangentes, dos quais foram consideradas neste estudo apenas as formas de vida não-arbóreas.

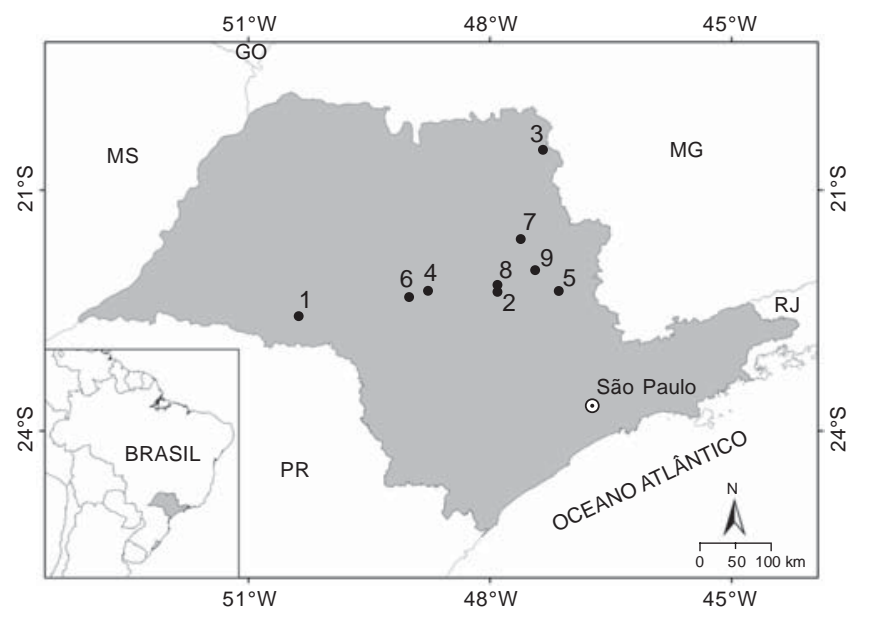

Figura 1. Localização das áreas de cerrado no Estado de São Paulo, utilizadas nas análises de similaridade florística: 1. Assis (este estudo). 2. Itirapina, (Tannus \& Assis 2004). 3. Franca (Araújo et al. 1999). 4. Agudos (Coral et al. 1990). 5. Moji Guaçu (Mantovani \& Martins 1993). 6. Bauru (Christianini \& Cavassan 1998). 7. Santa Rita do Passa Quatro (Batalha \& Mantovani 2001). 8. Brotas (Durigan et al. 2004). 9. Pirassununga, (Batalha et al. 1997).

Figure 1. Cerrado areas in São Paulo State, included in the floristic similarity analysis: 1. Assis (this study). 2. Itirapina (Tannus \& Assis 2004). 3. Franca (Araújo et al. 1999). 4. Agudos (Coral et al. 1990). 5. Moji Guaçu (Mantovani \& Martins 1993). 6. Bauru (Christianini \& Cavassan 1998). 7. Santa Rita do Passa Quatro (Batalha \& Mantovani 2001). 8. Brotas (Durigan et al. 2004). 9. Pirassununga, (Batalha et al. 1997).

Para montagem da matriz de presença e ausência das espécies em cada uma das áreas, efetuou-se, primeiramente, a checagem de sinonímia botânica. Utilizando-se a matriz, foi realizada análise de agrupamento pela média (UPGMA), utilizando-se o programa NT-SYS para Windows, versão 2.10, para obtenção de um dendrograma. O dendrograma foi transformado numa matriz cofenética, sendo esta correlacionada com a matriz de similaridade inicial através do teste de Mantel, utilizando-se 1000 permutações.

\section{Resultados}

Flora não-arbórea da Estação Ecológica de Assis - Foram registradas, até o momento, na Estação Ecológica de Assis, 301 espécies vegetais não-arbóreas, pertencentes a 199 gêneros e 61 famílias de fanerógamas (tabela 1). As famílias melhor representadas em número de espécies foram Fabaceae (32 espécies), Asteraceae (29), Bignoniaceae (18), Poaceae (18), Rubiaceae (16), Melastomataceae (12) e Myrtaceae (12). Mimosa foi o gênero com o maior 
número de espécies registradas (nove), seguido por Eugenia e Vernonia, com sete espécies cada, Arrabidaea, com seis espécies e Chamaecrista, com cinco espécies, uma delas com quatro variedades (tabela 1). A maior riqueza florística para espécies fanerógamas nãoarbóreas foi registrada na fisionomia cerrado sensu stricto, com 147 espécies (49 exclusivas desta fisionomia), seguido pelo cerradão, com 48 espécies (20 exclusivas), campo úmido, com 47 espécies (10 exclusivas) e, por último, a mata ciliar, com 15 espécies (11 exclusivas). Cerca de $14 \%$ das espécies foram registradas em duas fisionomias, geralmente ocorrendo em cerrado sensu stricto e cerradão (figura 2).

As espécies não-arbóreas da Estação Ecológica de Assis (tabela 1) estão assim distribuídas entre as formas de vida: 94 arbustos (30,9\%), 43 subarbustos (14,1\%), 110 ervas $(36,2 \%), 55$ trepadeiras $(18,1 \%)$ e duas palmeiras $(0,7 \%)$.

Tabela 1. Lista de táxons fanerogâmicos não arbóreos da Estação Ecológica de Assis, Estado de São Paulo. (FEA = número de registro na coleção botânica da Floresta Estadual de Assis; SPSF = número de registro no herbário SPSF; s.n. = material vegetativo não depositado em herbários).

Table 1. Checklist of phanerogamic non-arboreal taxa from Assis Ecological Station, Sao Paulo State, Brazil. $(F E A=$ voucher number at "Floresta Estadual de Assis" Botanical Collection; SPSF = voucher number at SPSF herbarium; s.n. = vegetative material not registered in herbaria).

\begin{tabular}{|c|c|c|c|}
\hline Família/Espécie & Hábito & Hábitat & № registro \\
\hline \multicolumn{4}{|l|}{ ACANTHACEAE } \\
\hline Geissomeria sp. \# & arbusto & cerrado & SPSF35881 \\
\hline Ruellia geminiflora Kunth & erva & campo úmido & s.n. \\
\hline \multicolumn{4}{|l|}{ ALISMATACEAE } \\
\hline Echinodorus longipetalus Micheli & erva & campo úmido & SPSF 35873 \\
\hline \multicolumn{4}{|l|}{ AMARANTHACEAE } \\
\hline Gomphrena virgata Mart. & erva & cerrado & s.n. \\
\hline \multicolumn{4}{|l|}{ ANACARDIACEAE } \\
\hline Anacardium humile A. St.-Hil. & subarbusto & cerrado & SPSF 35915 \\
\hline \multicolumn{4}{|l|}{ ANNONNACEAE } \\
\hline Annona nutans R. E. Fr. & arbusto & cerrado & s.n. \\
\hline Annona dioica A. St.-Hil. & arbusto & cerrado & s.n. \\
\hline Duguetia furfuracea (A. St.-Hil.) Saff. & arbusto & cerrado/cerradão & SPSF 35930 \\
\hline \multicolumn{4}{|l|}{ APIACEAE } \\
\hline Eryngium ebracteatum Lam. & erva & campo úmido & SPSF 36224 \\
\hline \multicolumn{4}{|l|}{ APOCYNACEAE } \\
\hline Blepharodon bicuspidatum E. Fourn. * & trepadeira & cerrado/cerradão & SPSF 35834 \\
\hline Forsteronia glabrescens Müll. Arg. & trepadeira & cerradão & FEA 638 \\
\hline Forsteronia pilosa (Vell.) Müll. Arg. *\# & trepadeira & cerradão & SPSF 36222 \\
\hline Mandevilla illustris (Vell.) Woodson & subarbusto & cerrado & FEA 954 \\
\hline Mandevilla velutina (Mart.) Woodson & subarbusto & cerrado & FEA 200 \\
\hline Metastelma guilleminianum Malme *\# & trepadeira & cerradão & FEA 381 \\
\hline Odontadenia lutea (Vell.) Markgr. & trepadeira & cerrado/cerradão & SPSF 35929 \\
\hline Oxypetalum appendiculatum Mart. * & trepadeira & cerradão & SPSF 35892 \\
\hline Schubertia grandiflora Mart. \# & trepadeira & cerrado & FEA 39 \\
\hline Temnadenia violacea (Vell.) Miers & trepadeira & cerrado/cerradão & SPSF 35813 \\
\hline \multicolumn{4}{|l|}{ ARECACEAE } \\
\hline Allagoptera campestris Kuntze & palmeira & cerrado & FEA 543 \\
\hline Butia paraguayensis (Barb. Rodr.) L.H. Bailey & palmeira & cerrado & FEA 576 \\
\hline \multicolumn{4}{|l|}{ ASTERACEAE } \\
\hline Achyrocline satureioides DC. & subarbusto & cerrado & FEA 394 \\
\hline
\end{tabular}


continuação

\begin{tabular}{|c|c|c|c|}
\hline Família/Espécie & Hábito & Hábitat & № registro \\
\hline Adenostemma viscosum J. R. Forst. \& G. Forst. & erva & cerradão/mata ciliar & FEA 89 \\
\hline Ageratum conyzoides $\mathrm{L}$. & erva & cerrado & SPSF 35931 \\
\hline Ambrosia psilostachya DC. & arbusto & cerrado & s.n. \\
\hline Aspilia latissima Malme & erva & cerrado & FEA 328 \\
\hline Baccharis dracunculifolia DC. & arbusto & cerrado/cerradão & SPSF 37025 \\
\hline Baccharis pseudotenuifolia L. Teodoro * & arbusto & cerrado & SPSF 36225 \\
\hline Baccharis trimera (Less.) DC. & erva & cerrado/campo úmido & FEA 549 \\
\hline Bidens gardneri Baker & erva & cerrado/cerradão & SPSF 37080 \\
\hline Callea sp. * & erva & cerrado & SPSF 35870 \\
\hline Dasyphillum brasiliense (Spreng.) Cabrera & arbusto & cerradão & FEA 896 \\
\hline Eupatorium pauciflorum Kunth & subarbusto & cerrado & SPSF 37031 \\
\hline Eupatorium sp. & arbusto & cerrado & SPSF 37032 \\
\hline Gochnatia barrosii Cabrera & arbusto & cerrado/cerradão & SPSF 37024 \\
\hline Mikania cordifolia Willd. * & trepadeira & cerradão & SPSF 37021 \\
\hline Mutisia coccinea A. St.-Hil. *\# & arbusto & mata ciliar & SPSF 35805 \\
\hline Pterocaulon alopecuroides (Lam.) DC. & erva & cerrado & FEA 442 \\
\hline Pterocaulon lanatum Kuntze *\# & erva & cerrado & SPSF 36991 \\
\hline Senecio brasiliensis (Spreng.) Less. * & erva & cerrado & SPSF 35855 \\
\hline Senecio leptolobus DC. \# & erva & cerrado & FEA 1110 \\
\hline Tridax procumbens L. \# & trepadeira & cerrado & FEA 445 \\
\hline Vernonia brasiliana (L.) Druce & arbusto & cerrado & FEA 620 \\
\hline Vernonia cotoneaster Less. \# & arbusto & cerrado & FEA 432 \\
\hline Vernonia florida Gardner \# & arbusto & cerrado & FEA 323 \\
\hline Vernonia herbacea (Vell.) Rusby * & erva & cerrado & SPSF 36232 \\
\hline Vernonia polyanthes Less. * & arbusto & cerrado & SPSF 37015 \\
\hline Vernonia rubriramea Mart. ex DC. & arbusto & cerrado & SPSF 36233 \\
\hline Vernonia scorpioides (Lam.) Pers. * & arbusto & cerrado/cerradão & SPSF 36992 \\
\hline Wedelia brachycarpa Baker & erva & cerrado & FEA 712 \\
\hline \multicolumn{4}{|l|}{ BEGONIACEAE } \\
\hline Begonia cucullata Willd. & erva & campo úmido & SPSF 35821 \\
\hline \multicolumn{4}{|l|}{ BIGNONIACEAE } \\
\hline Adenocalymma bracteatum DC. \# & trepadeira & mata ciliar & FEA 504 \\
\hline Amphilophium paniculatum (L.) Kunth \# & trepadeira & cerradão & FEA 742 \\
\hline Anemopaegma arvense (Vell.) Stellfeld ex J. F. Souza & subarbusto & cerrado & FEA 657 \\
\hline Arrabidaea brachypoda Bureau & arbusto & cerrado/cerradão & SPSF 35848 \\
\hline Arrabidaea chica (Humb. \& Bonpl.) Verl. *\# & arbusto & cerrado & SPSF 36180 \\
\hline Arrabidaea florida DC. & trepadeira & cerradão & SPSF 35846 \\
\hline Arrabidaea formosa (Bureau) Sandwith *\# & trepadeira & cerradão & SPSF 36181 \\
\hline Arrabidaea pulchella (Cham.) Bureau. *\# & trepadeira & cerradão & SPSF 36179 \\
\hline Arrabidaea pulchra (Cham.) Sandwith \# & trepadeira & cerradão & SPSF 36178 \\
\hline Distictella elongata Urb. & trepadeira & cerradão & SPSF 36176 \\
\hline Fridericia speciosa Mart. \# & trepadeira & cerradão & SPSF 37030 \\
\hline Jacaranda caroba DC. & arbusto & cerrado/cerradão & SPSF 35918 \\
\hline Jacaranda decurrens Cham. & subarbusto & cerrado & FEA 148 \\
\hline Jacaranda rufa Silva Manso & subarbusto & cerrado & FEA 677 \\
\hline Memora axillaris K. Schum. & arbusto & cerrado/cerradão & SPSF 35824 \\
\hline Phryganocydia corymbosa Bureau ex K. Schum. \# & trepadeira & cerradão & SPSF 35888 \\
\hline Pyrostegia venusta Miers & trepadeira & cerradão & SPSF 35922 \\
\hline Zeyheria montana Mart. & arbusto & cerrado & FEA 1215 \\
\hline \multicolumn{4}{|l|}{ BIXACEAE } \\
\hline Cochlospermum regium (Schrank) Pilg. & arbusto & cerrado & SPSF 36177 \\
\hline
\end{tabular}


continuação

\begin{tabular}{|c|c|c|c|}
\hline Família/Espécie & Hábito & Hábitat & № registro \\
\hline \multicolumn{4}{|l|}{ BROMELIACEAE } \\
\hline Acanthostachys strobilacea (Schult. \& Schult.f.) Klotzch & erva & cerradão & FEA 3508 \\
\hline Aechmea bromeliifolia (Rudge) Baker & erva & cerradão & FEA 3509 \\
\hline Aechmea distichanta Lem. \# & erva & cerradão & FEA 766 \\
\hline Ananas ananassoides (Baker) L. B. Sm. & erva & cerrado/cerradão & SPSF 35879 \\
\hline Bromelia balansae Mez. & erva & cerradão & FEA 956 \\
\hline Dyckia tuberosa (Vell.) Beer * & erva & cerrado & SPSF 35829 \\
\hline \multicolumn{4}{|l|}{ CACTACEAE } \\
\hline Epyphyllum phyllanthus (L.) Haw. & erva & cerradão & FEA 3510 \\
\hline \multicolumn{4}{|l|}{ CAMPANULACEAE } \\
\hline Siphocampylus nitidus Pohl \# & trepadeira & mata ciliar & FEA 520 \\
\hline \multicolumn{4}{|l|}{ CELASTRACEAE } \\
\hline Peritassa campestris (Cambess.) A. C. Sm. & subarbusto & cerrado & SPSF 35869 \\
\hline Tontelea micrantha (Mart. ex Schult.) A. C. Sm. & subarbusto & cerrado & FEA 542 \\
\hline \multicolumn{4}{|l|}{ COMMELINACEAE } \\
\hline Commelina erecta $\mathrm{L}$. & erva & cerrado/campo úmido & SPSF 35854 \\
\hline Dichorisandra sp. & erva & mata ciliar & s.n. \\
\hline \multicolumn{4}{|l|}{ CONVOLVULACEAE } \\
\hline Evolvulus pterocaulon Moric. \# & erva & cerrado & SPSF 35819 \\
\hline Ipomoea grandifolia (Dammer) O’Donell \# & trepadeira & cerrado & FEA 449 \\
\hline Ipomoea $\mathrm{sp}$. & trepadeira & cerrado & SPSF 37033 \\
\hline Jacquemontia evolvuloides Meisn. *\# & trepadeira & cerradão & SPSF 35851 \\
\hline Merremia macrocalyx (Ruiz \& Pav.) O’Donell & trepadeira & cerradão & SPSF 37028 \\
\hline \multicolumn{4}{|l|}{ CYPERACEAE } \\
\hline Cyperus haspan L.* & erva & campo úmido & SPSF 36226 \\
\hline Cyperus virens Michx. *\# & erva & campo úmido & SPSF 37081 \\
\hline Fimbristylis sp. $*$ & erva & campo úmido & SPSF 36227 \\
\hline Lipocarpha sp. * & erva & campo úmido & SPSF 36228 \\
\hline Scleria latifolia Sw. * & erva & campo úmido & SPSF 36229 \\
\hline Scleria mitis P. J. Bergius & erva & campo úmido & SPSF 36230 \\
\hline Rhynchospora albiceps Kunth * & erva & campo úmido & SPSF 37085 \\
\hline Rhynchospora sp. & erva & campo úmido & SPSF 37091 \\
\hline \multicolumn{4}{|l|}{ DILLENIACEAE } \\
\hline Davilla elliptica A. St.-Hil. & arbusto/trepadeira & cerrado/cerradão & SPSF 35865 \\
\hline Doliocarpus dentatus Standl. \# & trepadeira & cerradão & SPSF 37000 \\
\hline \multicolumn{4}{|l|}{ DIOSCOREACEAE * } \\
\hline Dioscorea sp. * & trepadeira & cerradão & SPSF 35871 \\
\hline \multicolumn{4}{|l|}{ DROSERACEAE * } \\
\hline Drosera communis A. St.-Hil. * & erva & campo úmido & SPSF 35827 \\
\hline \multicolumn{4}{|l|}{ ERIOCAULACEAE * } \\
\hline Actinocephalus sp. *\# & erva & campo úmido & SPSF 37028 \\
\hline Leiothrix cf. flavescens (Bong.) Ruhland *\# & erva & campo úmido & SPSF 37020 \\
\hline Syngonanthus caulescens Ruhland * & erva & campo úmido & SPSF 36174 \\
\hline \multicolumn{4}{|l|}{ ERYTHROXYLACEAE } \\
\hline Erythroxylum campestre A. St.-Hil. * & arbusto & cerrado & SPSF 35907 \\
\hline Erythroxylum cuneifolium (Mart.) O. E. Schulz & arbusto & cerrado/cerradão & SPSF 35975 \\
\hline Erythroxylum pelleterianum A. St.-Hil. & arbusto & cerrado/cerradão & FEA 188 \\
\hline \multicolumn{4}{|l|}{ EUPHORBIACEAE } \\
\hline Actinostemon concepcionis Pax \& K. Hoffm. \# & arbusto & cerrado & SPSF 35844 \\
\hline
\end{tabular}


continuação

\begin{tabular}{llll}
\hline Família/Espécie & Hábito & Hábitat & No registro \\
\hline Cnidoscolus albomaculatus I. M. Johnst. \# & erva & cerrado & FEA 857 \\
Croton glandulosus L. * & arbusto & cerrado & SPSF 37003 \\
Croton lobatus L. & arbusto & cerrado & SPSF 35875 \\
Croton lundianus Müll. Arg. *\# & erva & cerrado & SPSF 35868 \\
Manihot caerulescens Pohl & arbusto & cerrado & SPSF 35836 \\
Manihot tripartita (Spr.) Müll. Arg. & arbusto & cerrado & SPSF 35908 \\
Sebastiania aff. hispida (Mart.) Pax \# & erva & cerrado & SPSF 37707
\end{tabular}

FABACEAE

Cercidae

Bauhinia rufa Steud.

Caesalpinoidae

Chamaecrista campestris H. S. Irwin \& Barneby *

Chamaecrista flexuosa (L.) Greene

Chamaecrista cathartica H. S. Irwin \& Barney

Chamaecrista desvauxii var. glauca (Hassl.) H. S.

Irwin \& Barneby

Chamaecrista desvauxii var. langsdorfii (Kunth ex

Vogel) H. S. Irwin \& Barneby \#

Chamaecrista desvauxii var. latistipula (Benth.)

G. P. Lewis *\#

Chamaecrista desvauxii var. molissima (Benth.) H. S.

Irwin \& Barneby \#

Chamaecrista rotundifolia (Pers.) Greene

Senna occidentalis (L.) Link \#

Senna rugosa (G. Don) H. S. Irwin \& Barneby

Senna silvestris (Vell.) H. S. Irwin \& Barneby

Senna splendida (Vog.) H. S. Irwin \& Barneby \#

Senna velutina (Vog.) H. S. Irwin \& Barneby *\#

Faboidae

Aeschynomene selloi Vog. \#

Andira humilis Mart.

Camptosema ellipticum (Desv.) Burkart

Centrosema pubescens Benth. \#

Crotalaria micans Link \#

Crotalaria martiana Benth. *\#

Desmodium incanum DC. *

Macroptilium lathyroides (L.) Urb.

Stylosanthes acuminata M. B. Ferreira \& Sousa Costa \# Stylosanthes capitata Vog.

arbusto

cerrado/cerradão

SPSF 36996

arbusto

subarbusto

arbusto

subarbusto

subarbusto

arbusto

subarbusto

erva

trepadeira

arbusto

arbusto

arbusto

arbusto

arbusto

subarbusto

trepadeira

erva

erva

erva

erva

erva

subarbusto

erva

arbusto

erva

arbusto

subarbusto

subarbusto

erva

subarbusto

subarbusto

arbusto

subarbusto

subarbusto cerrado

cerrado

cerrado

cerrado

cerrado

cerrado

cerrado

cerrado

cerradão

cerrado/cerradão

cerradão

cerrado

cerrado

SPSF 35856

SPSF 37008

SPSF 35892

FEA 353

SPSF 35905

SPSF 35822

SPSF 37022

FEA 599

FEA 497

SPSF 37002

SPSF 36993

FEA 889

FEA 447

SPSF 35877

cerrado

FEA 195

cerrado

cerrado/cerradão

cerrado

cerrado

cerradão

cerrado

cerrado

cerrado

cerrado

cerrado

cerrado

SPSF 35898

SPSF 35872

FEA 637

SPSF 37125

SPSF 35849

SPSF 35913

FEA 3311

FEA 425

s.n.

SPSF 37019

cerrado

FEA 664

cerrado

cerrado

cerrado

cerrado

cerrado

cerrado

cerrado

cerrado
SPSF 35845

SPSF 35883

FEA 1135

FEA 411

FEA 185

SPSF 35857

SPSF 35840

SPSF 37026 
continuação

\begin{tabular}{|c|c|c|c|}
\hline Família/Espécie & Hábito & Hábitat & № registro \\
\hline \multicolumn{4}{|l|}{ GENTIANACEAE } \\
\hline \multicolumn{4}{|l|}{ Irlbachia alata subsp. viridiflora (Mart.) Persoon \& } \\
\hline Maas * & erva & campo úmido & SPSF 35830 \\
\hline Schultesia guianensis (Aubl.) Malme & erva & campo úmido & SPSF 35820 \\
\hline \multicolumn{4}{|l|}{ GESNERIACEAE } \\
\hline Sinningia allagophylla (Mart.) Wihler \# & subarbusto & cerrado & SPSF 35812 \\
\hline Sinningia elatior (Kunth) Chautems * & erva & campo úmido & FEA 363 \\
\hline \multicolumn{4}{|l|}{ JUNCACEAE } \\
\hline Juncus sellowianus Kunth \# & erva & campo úmido/brejo & FEA 96 \\
\hline \multicolumn{4}{|l|}{ LAMIACEAE } \\
\hline Eriope crassipes Benth. & arbusto & cerrado & FEA 865 \\
\hline Hyptis crinita Benth. & erva & cerrado & SPSF 36995 \\
\hline Hyptis densiflora Pohl ex Benth. \# & erva & cerrado & FEA 2385 \\
\hline Hyptis glomerata Mart. ex Schrank & arbusto & cerrado & FEA 415 \\
\hline Hyptis suaveolens (L.) Poit. & erva & cerrado & FEA 451 \\
\hline Hyptis villosa Pohl ex Benth. *\# & erva & cerrado & SPSF 35909 \\
\hline Hyptis sp. & erva & cerrado & SPSF 35838 \\
\hline Hypenia macrantha (A. St.-Hil. ex Benth.) Harley *\# & trepadeira & cerrado & SPSF 35859 \\
\hline Peltodon tomentosus Pohl & erva & cerrado & FEA 699 \\
\hline \multicolumn{4}{|l|}{ LAURACEAE } \\
\hline Aiouea trinervis Meisn. \# & arbusto & cerrado & FEA 536 \\
\hline \multicolumn{4}{|l|}{ LOGANIACEAE } \\
\hline Strychnos brasiliensis Mart. \# & trepadeira & cerradão & SPSF 35925 \\
\hline \multicolumn{4}{|l|}{ LYTHRACEAE } \\
\hline Cuphea carthagenensis (Jacq.) J. F. Macbr. * & erva & cerrado & FEA 3191 \\
\hline \multicolumn{4}{|l|}{ MALPIGHIACEAE } \\
\hline Banisteriopsis adenopoda (A. Juss.) B. Gates \# & trepadeira & cerradão & SPSF 35928 \\
\hline Banisteriopsis campestris (A. Juss.) Little & arbusto & cerrado & FEA 729 \\
\hline Banisteriopsis pubipetala (A. Juss.) Cuatrec. & trepadeira & cerradão & SPSF 37010 \\
\hline Banisteriopsis stellaris (Griseb.) B. Gates & trepadeira & cerrado & SPSF 35927 \\
\hline Byrsonima intermedia A. Juss. & arbusto & cerrado/cerradão & SPSF 37023 \\
\hline Byrsonima subterranea Brade \& Markgr. & subarbusto & cerrado & FEA 731 \\
\hline Heteropterys byrsonimifolia A. Juss. & arbusto & cerrado/cerradão & SPSF 37011 \\
\hline Heteropterys pteropetala A. Juss. \# & subarbusto & cerrado & FEA 153 \\
\hline Mascagnia cordifolia (A. Juss.) Griseb. & trepadeira & cerradão & SPSF 35921 \\
\hline Peixotoa hirta Mart. ex A. Juss. \# & arbusto & cerrado & FEA 740 \\
\hline Peixotoa tomentosa A. Juss. & arbusto & cerrado & FEA 942 \\
\hline Stigmaphyllon lalandianum A. Juss. \# & trepadeira & cerrado & FEA 839 \\
\hline Schwannia sp. \# & trepadeira & cerradão & s.n. \\
\hline Tetrapterys sp. \# & trepadeira & cerrado & s.n. \\
\hline \multicolumn{4}{|l|}{ MALVACEAE } \\
\hline Pavonia guerkeana R. E. Fr. * & arbusto & cerrado & SPSF 37005 \\
\hline Peltaea polymorpha (A. St.-Hil.) Krapov. \& Cristóbal & erva & cerrado & SPSF 35826 \\
\hline Sida cerradoensis Krapov. & subarbusto & cerrado & s.n. \\
\hline Sida cordifolia $\mathrm{L}$. & subarbusto & cerrado & FEA 492 \\
\hline Sida linifolia Cav. & subarbusto & cerrado & s.n. \\
\hline Sida spinosa $\mathrm{L}$. & subarbusto & cerrado & FEA 2360 \\
\hline Sida sp. & subarbusto & cerrado & SPSF 35867 \\
\hline Waltheria douradinha A. St.-Hil. *\# & subarbusto & cerrado & SPSF 35869 \\
\hline Waltheria communis A. St.-Hil. & subarbusto & cerrado & s.n. \\
\hline
\end{tabular}


continuação

\begin{tabular}{|c|c|c|c|}
\hline Família/Espécie & Hábito & Hábitat & № registro \\
\hline \multicolumn{4}{|l|}{ MAYACACEAE * } \\
\hline Mayaca sellowiana Kunth * & erva & campo úmido & SPSF 36990 \\
\hline \multicolumn{4}{|l|}{ MELASTOMATACEAE } \\
\hline Acisanthera alsinaefolia Triana & erva & campo úmido & SPSF 35831 \\
\hline Desmoscelis villosa (Aubl.) Naudin \# & erva & cerrado & FEA 824 \\
\hline Leandra lacunosa Cogn. & arbusto & mata ciliar & SPSF 35900 \\
\hline Miconia albicans (Sw.) Steud. & arbusto & cerrado/cerradão & SPSF 35912 \\
\hline Miconia chamissois Naudin & arbusto & campo úmido/brejo & SPSF 36994 \\
\hline Miconia fallax DC. & arbusto & cerrado/cerradão & SPSF 35833 \\
\hline Miconia langsdorffii Cogn. & arbusto & cerradão & SPSF 35815 \\
\hline Miconia stenostachya DC. * & arbusto & cerrado/cerradão & SPSF 37026 \\
\hline Pterolepis glomerata Miq. \# & subarbusto & cerrado & FEA 240 \\
\hline Rhynchanthera dichotoma DC. & subarbusto & campo úmido & SPSF 37012 \\
\hline Tibouchina cerastifolia Cogn. \# & erva & campo úmido & FEA 695 \\
\hline Tibouchina gracilis (Bonpl.) Cogn. & erva & campo úmido & SPSF 35844 \\
\hline \multicolumn{4}{|l|}{ MENISPERMACEAE } \\
\hline Cissampelos ovalifolia DC. & erva & cerrado & SPSF 35816 \\
\hline Cissampelos cf. andromorpha DC. *\# & trepadeira & mata ciliar & SPSF 35841 \\
\hline Cissampelos pareira L. \# & trepadeira & cerrado/cerradão & FEA 925 \\
\hline \multicolumn{4}{|l|}{ MYRSINACEAE } \\
\hline Cybianthus detergens Mart. \# & arbusto & cerradão & FEA 77 \\
\hline \multicolumn{4}{|l|}{ MYRTACEAE } \\
\hline Campomanesia adamantium Blume & arbusto & cerrado & SPSF 37017 \\
\hline Eugenia bimarginata DC. & arbusto & cerrado & SPSF 35890 \\
\hline Eugenia dysenterica DC. & arbusto & cerrado & SPSF 36223 \\
\hline Eugenia klotzschiana O. Berg & arbusto & cerrado & FEA 210 \\
\hline Eugenia obversa $\mathrm{O}$. Berg *\# & subarbusto & cerrado & SPSF 35911 \\
\hline Eugenia pitanga (O. Berg ex Mart.) Kiaersk. & subarbusto & cerrado & FEA 208 \\
\hline Eugenia punicifolia (Kunth) DC. & arbusto & cerrado & SPSF 35861 \\
\hline Eugenia racemulosa $\mathrm{O}$. Berg \# & arbusto & cerrado & FEA 205 \\
\hline Myrcia breviramis (O. Berg) D. Legrand \# & arbusto & cerrado & FEA 1340 \\
\hline Psidium australe Cambess. & arbusto & cerrado & FEA 207 \\
\hline Psidium cinereum Mart. ex DC. * & arbusto & cerrado & FEA 2344 \\
\hline Psidium microcarpum Cambess. *\# & arbusto & cerrado/cerradão & SPSF 35839 \\
\hline \multicolumn{4}{|l|}{ OCHNACEAE } \\
\hline Ouratea nana Engl. \# & subarbusto & cerrado & SPSF 35880 \\
\hline Sauvagesia racemosa A. St.-Hil. & subarbusto & campo úmido & SPSF 35855 \\
\hline \multicolumn{4}{|l|}{ ONAGRACEAE } \\
\hline Ludwigia elegans (Cambess.) H. Hara \# & erva & campo úmido & FEA 400 \\
\hline Ludwigia nervosa (Poir.) H. Hara & arbusto & campo úmido & SPSF 35882 \\
\hline Ludwigia octovalvis (Jacq.) P. H. Raven & erva & campo úmido & SPSF 35904 \\
\hline \multicolumn{4}{|l|}{ ORCHIDACEAE } \\
\hline Catasetum fimbriatum Lindl. \& Paxton *\# & erva & cerradão & FEA 1374 \\
\hline Epidendrum elongatum Jacq. \# & erva & cerrado/cerradão & SPSF 35899 \\
\hline Rodriguezia decora (Lem.) Rchb. F. *\# & erva & campo úmido & FEA 1200 \\
\hline Zygopetalum maxillare Lodd. \# & erva & mata ciliar & SPSF 35917 \\
\hline \multicolumn{4}{|l|}{ OXALIDACEAE } \\
\hline Oxalis grisea A. St.-Hil. \& Naudin & subarbusto & cerrado & FEA 738 \\
\hline
\end{tabular}


continuação

\begin{tabular}{|c|c|c|c|}
\hline Família/Espécie & Hábito & Hábitat & № registro \\
\hline \multicolumn{4}{|l|}{ PASSIFLORACEAE } \\
\hline Passiflora cincinnata Mast. \# & trepadeira & cerradão & SPSF 35910 \\
\hline \multicolumn{4}{|l|}{ PHYTOLACACEAE * } \\
\hline Phytollaca thyrsiflora Fenzl ex Schimdt *\# & erva & cerrado & SPSF 36175 \\
\hline \multicolumn{4}{|l|}{ PIPERACEAE } \\
\hline Piper aduncum L. \# & arbusto & mata ciliar & SPSF 35862 \\
\hline Piper crassinervium Kunth *\# & arbusto & mata ciliar & SPSF 35863 \\
\hline Piper mollicomum Kunth \# & arbusto & mata ciliar & s.n. \\
\hline Piper tuberculatum Jacq. \# & arbusto & mata ciliar & s.n. \\
\hline Piper sp. & arbusto & campo úmido & SPSF 35864 \\
\hline Pothomorphe umbellata (L.) Miq. \# & arbusto & mata ciliar & FEA 1497 \\
\hline \multicolumn{4}{|l|}{ POACEAE } \\
\hline Andropogon bicornis L. *\# & erva & campo úmido & FEA 3186 \\
\hline Andropogon selloanus (Hack.) Hack. * & erva & campo úmido & SPSF 37055 \\
\hline Axonopus affinis Chase * & erva & campo úmido & FEA 3185 \\
\hline Axonopus siccus Kuhlm. * & erva & campo úmido & FEA 3183 \\
\hline Axonopus suffultus (Mikan ex Trin.) Parodi * & erva & campo úmido & FEA 3188 \\
\hline Chloris sp. & erva & cerrado & SPSF 35919 \\
\hline Eragrostis leucosticta Nees. ex Döll * & erva & campo úmido & FEA 3179 \\
\hline Eriochrysis cayennensis P. Beauv. * & erva & campo úmido & FEA 3178 \\
\hline Gymnopogon foliosus (Willd.) Nees. * & erva & cerrado & FEA 3187 \\
\hline Ichnanthus inconstans Döll * & erva & campo úmido & SPSF 37066 \\
\hline Melinis minutiflora P. Beauv. & erva & cerrado & s.n. \\
\hline Merostachys skvortzovii Sendulsky *\# & erva & cerrado & SPSF 37013 \\
\hline Panicum campestre Ness. ex Trin. * & erva & campo úmido & FEA 3184 \\
\hline Panicum schwackeanum Mez. * & erva & campo úmido & FEA 3182 \\
\hline Paspalum cordatum Hack. * & erva & campo úmido & SPSF 37056 \\
\hline Rhynchelytrum repens (Willd.) C. E. Hubb. & erva & cerrado & FEA 508 \\
\hline Schizachyrium condensatum (Kunth) Nees * & erva & campo úmido & FEA 3190 \\
\hline Setaria sp. & erva & mata ciliar & FEA 2381 \\
\hline \multicolumn{4}{|l|}{ POLYGALACEAE } \\
\hline Bredemeyera floribunda Willd. & arbusto & cerrado/cerradão & SPSF 37014 \\
\hline Securidaca rivinaefolia A. St.-Hil. *\# & trepadeira & cerradão & SPSF 35894 \\
\hline Polygala sp. * & erva & cerrado & SPSF 35886 \\
\hline \multicolumn{4}{|l|}{ PORTULACEAE } \\
\hline Portulaca pilosa $\mathrm{L} . \#$ & erva & cerrado & FEA 500 \\
\hline \multicolumn{4}{|l|}{ RHAMNACEAE } \\
\hline Gouania ulmifolia Hook. \& Arn. *\# & trepadeira & cerradão & SPSF 37009 \\
\hline Gouania velutina Reissek \# & trepadeira & cerradão & SPSF 36999 \\
\hline \multicolumn{4}{|l|}{ ROSACEAE } \\
\hline Rubus brasiliensis Mart. & trepadeira & cerrado & SPSF 35896 \\
\hline \multicolumn{4}{|l|}{ RUBIACEAE } \\
\hline Alibertia concolor (Cham.) K. Schum. & arbusto & cerrado/cerradão & SPSF 35860 \\
\hline Borreria latifolia (Aubl.) K. Schum. \# & erva & cerrado & FEA 551 \\
\hline Borreria cf. verticillata $\mathrm{G}$. Mey. * & erva & cerrado & SPSF 35861 \\
\hline Coccocypselum lanceolatum Pers. & erva & cerrado/cerradão & SPSF 35976 \\
\hline \multicolumn{4}{|l|}{ Declieuxia fruticosa (Willd. ex Roem. \& Schult.) } \\
\hline Kuntze * & subarbusto & campo úmido & SPSF 35832 \\
\hline
\end{tabular}


continuação

\begin{tabular}{|c|c|c|c|}
\hline Família/Espécie & Hábito & Hábitat & № registro \\
\hline Diodia cf. alata Nees \& Mart. \# & erva & cerrado & FEA 424 \\
\hline Diodia sp. & erva & cerrado & s.n. \\
\hline Manettia ignita K. Schum. \# & trepadeira & cerradão & FEA 431 \\
\hline Palicourea marcgravii A. St.-Hil. \# & arbusto & cerrado & FEA 389 \\
\hline Palicourea rigida Kunth & arbusto & cerrado/campo úmido & SPSF 35825 \\
\hline Psychotria anceps Kunth * & arbusto & campo úmido & SPSF 35837 \\
\hline Psychotria barbiflora DC. & arbusto & cerrado & FEA 232 \\
\hline Psychotria carthagenensis Jacq. & arbusto & cerradão & FEA 913 \\
\hline Psychotria sessilis (Vell.) Müll. Arg. & arbusto & cerrado/cerradão & SPSF 35876 \\
\hline Psychotria velloziana Benth. & arbusto & cerradão & SPSF 35858 \\
\hline Tocoyena formosa K. Schum. & arbusto & cerrado & SPSF 37006 \\
\hline \multicolumn{4}{|l|}{ SAPINDACEAE } \\
\hline Paullinia elegans Cambess. & trepadeira & mata ciliar & FEA 482 \\
\hline Serjania erecta Radlk. & subarbusto & cerrado & FEA 378 \\
\hline Serjania fuscifolia Radlk. \# & trepadeira & cerrado & FEA 475 \\
\hline Serjania lethalis A.St.-Hil. & trepadeira & cerradão & FEA 558 \\
\hline Serjania multiflora Cambess. \# & trepadeira & cerrado/cerradão & FEA 521 \\
\hline Serjania sp. & trepadeira & cerradão & s.n. \\
\hline \multicolumn{4}{|l|}{ SMILACACEAE } \\
\hline Smilax brasiliensis Spreng. *\# & trepadeira & cerrado/cerradão & SPSF 37033 \\
\hline Smilax campestris Griseb. * & trepadeira & cerrado & SPSF 35903 \\
\hline Smilax fluminensis Steud. \# & trepadeira & cerradão & SPSF 35893 \\
\hline \multicolumn{4}{|l|}{ SOLANACEAE } \\
\hline Cestrum lanceolatum Miers \# & arbusto & cerradão & FEA 93 \\
\hline Cestrum sendtnerianum Mart. ex Sendtn. & arbusto & cerradão & SPSF 35892 \\
\hline Solanum americanum Mill. & erva & cerradão & SPSF 36998 \\
\hline Solanum lycocarpum A. St.-Hil. & arbusto & cerrado & SPSF 37029 \\
\hline Solanum paniculatum L. & arbusto & cerrado/cerradão & SPSF 35923 \\
\hline Solanum platanifolium Hook. \# & erva & cerrado/cerradão & FEA 927 \\
\hline Solanum sisymbrifolium Lam. \# & subarbusto & cerrado & SPSF 37016 \\
\hline \multicolumn{4}{|l|}{ TURNERACEAE * } \\
\hline Piriqueta rosea Urb. * & erva & cerrado & SPSF 37027 \\
\hline \multicolumn{4}{|l|}{ VERBENACEAE } \\
\hline Lantana camara L. & arbusto & cerrado/cerradão & FEA 634 \\
\hline Lantana trifolia Cham. \# & subarbusto & cerrado & FEA 579 \\
\hline Lippia balansae Briq. & arbusto & cerrado/cerradão & SPSF 35889 \\
\hline Lippia lupulina Cham. & erva & cerrado & SPSF 35890 \\
\hline Petrea volubilis L. *\# & trepadeira & mata ciliar & SPSF 35897 \\
\hline Stachytarpheta elatior Schrad. ex Schult. \# & erva & cerrado & SPSF 35842 \\
\hline \multicolumn{4}{|l|}{ VITACEAE } \\
\hline Cissus erosa Rich. & arbusto & cerrado/cerradão & FEA 310 \\
\hline \multicolumn{4}{|l|}{ XYRIDACEAE } \\
\hline Xyris jupicai Rich. * & erva & campo úmido & SPSF 35828 \\
\hline Xyris savanensis Miq. * & erva & campo úmido & SPSF 35818 \\
\hline Xyris tenella Kunth *\# & erva & campo úmido & SPSF 35817 \\
\hline \multicolumn{4}{|l|}{ ZINGIBERACEAE } \\
\hline Hedychium coronarium J. König. * & erva & campo úmido/brejo & SPSF 35850 \\
\hline
\end{tabular}

* Novas ocorrências (táxons não amostrados por Durigan et al. 1999); \# táxons exclusivos da Estação Ecológica de Assis; * New occurrences (taxa not recorded by Durigan et al. 1999); \# exclusive taxa in Estação Ecológica de Assis. 


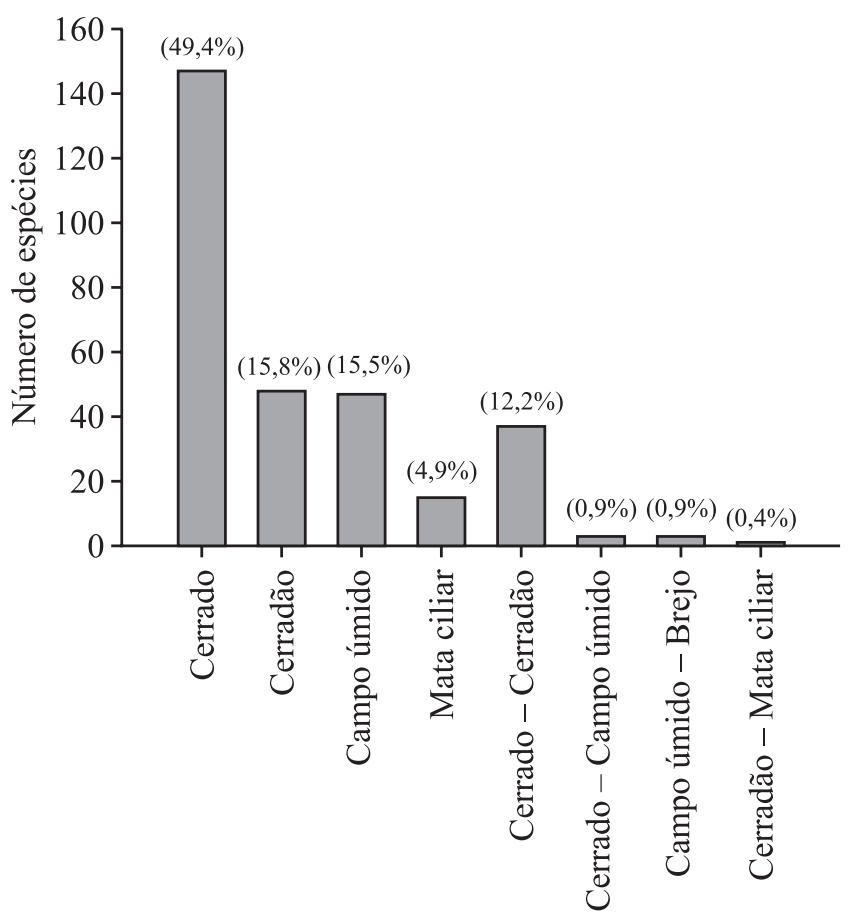

Fisionomias

Figura 2. Distribuição das espécies não-arbóreas nas diferentes fisionomias do Cerrado na Estação Ecológica de Assis.

Figure 2. Distribution of non-arboreal species among different Cerrado physiognomies at Estação Ecológica de Assis

Novas ocorrências - Considerando-se apenas os dados obtidos após a última publicação sobre a flora local (Durigan et al. 1999), foram acrescentadas por este estudo 88 espécies (ou 41\%) e oito famílias (Apiaceae, Dioscoreaceae, Droseraceae, Eriocaulaceae, Mayacaceae, Phytolaccaceae, Turneraceae e Zingiberaceae) à flora anteriormente conhecida.

A ampliação da lista de espécies não-arbóreas da Estação Ecológica de Assis deveu-se principalmente a informações provenientes das coletas efetuadas nas fisionomias cerrado sensu stricto e campo úmido, sendo que nesta última foi encontrada a maioria das novas ocorrências de famílias. Das 88 novas ocorrências, 33 (38\%) foram registradas exclusivamente no cerrado sensu stricto, 33 (38\%) no campo úmido, 13 (15\%) no cerradão (a maioria trepadeiras), cinco novas ocorrências em cerrado e cerradão e quatro em mata ciliar.

Ocorrência de espécies exclusivas da Estação Ecológica Assis - Comparando-se os dados totais deste com outros estudos que tratam da flora não-arbórea em áreas de cerrado no Estado de São Paulo, verificou-se que 102 espécies têm ocorrência exclusiva na Estação Ecológica de Assis. Este número corresponde a $34 \%$ das espécies não-arbóreas registradas até o momento nesta unidade de conservação. Dentre as espécies exclusivas predominam as ervas (30,4\%, com 31 espécies), seguidas das trepadeiras (27,5\%, 28 espécies), arbustos (24,5\%, 25 espécies) e subarbustos $(17,6 \%, 18$ espécies).

Similaridade florística entre áreas - A similaridade florística da flora não-arbórea da Estação Ecológica de Assis com as outras áreas analisadas foi baixa. A maior similaridade foi encontrada entre Assis e Emas (20,3\%), seguida por Santa Rita do Passa Quatro (19,8\%). Os menores índices de similaridade foram encontrados entre Assis e os levantamentos realizados em Agudos (6,3\%), Franca $(6,2 \%)$ e Bauru (1,8\%). A correlação entre a matriz de similaridade original e a matriz cofenética foi alta $(r=0,98)$, sendo significativas as relações apresentadas na Figura 3, de acordo com o teste de Mantel $(P<0.01)$.

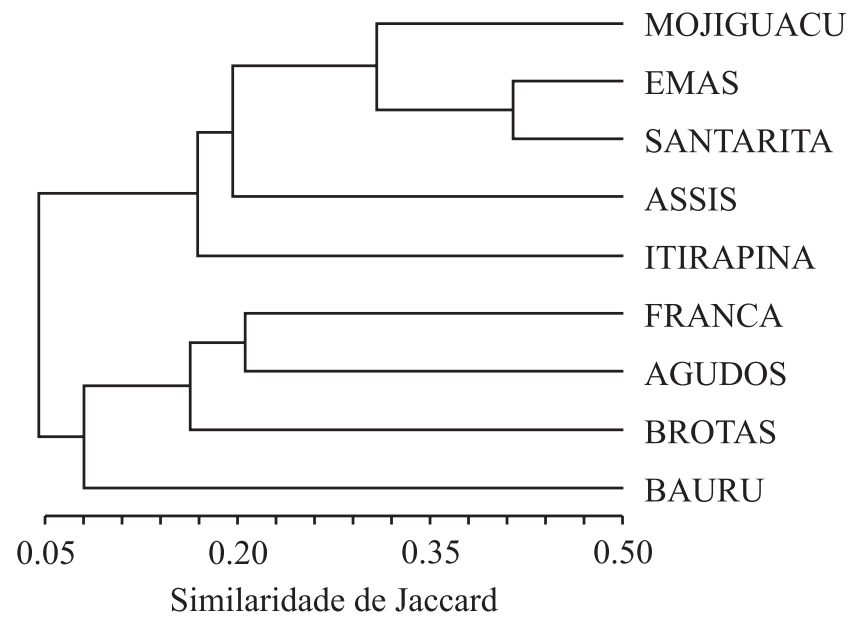

Figura 3. Dendrograma de análise de agrupamento pela média (UPGMA), utilizando o índice de similaridade de Jaccard, aplicado a espécies não-arbóreas registradas em nove áreas de Cerrado no Estado de São Paulo (localidades mapeadas na Figura 1).

Figure 3. Cluster analysis dendrogram (UPGMA) based upon Jaccard's Similarity Index, applied to non-arboreal species occurring in nine cerrado sites in the state of São Paulo, Brazil (localities mapped at Figure 1).

\section{Discussão}

A riqueza da flora fanerogâmica não-arbórea na Estação Ecológica de Assis (301 espécies) foi inferior à encontrada em áreas de cerrado de Moji-Guaçu por Mantovani \& Martins (1993) com 402 espécies, e também ao registrado em Itirapina, por Tannus \& Assis 
(2004) com 384 espécies. Foi superior, porém, à maioria dos estudos realizados sobre vegetação não-arbórea em outras áreas de cerrado no Estado de São Paulo: o cerrado de Emas, em Pirassununga, com 259 espécies (Batalha et al. 1997); Santa Rita do Passa Quatro, com 141 espécies amostradas por Weiser \& Godoy (2001) e 236 espécies amostradas por Batalha \& Mantovani (2001); Bauru, onde Christianini \& Cavassan (1998) amostraram 52 espécies; Agudos, com 70 espécies amostradas por Coral et al. (1991); Franca, onde Araújo et al. (1999) registraram 36 espécies e, em Brotas, Durigan et al. (2002) mencionaram 29 espécies. Cabe ressaltar que alguns desses estudos foram fitossociológicos, com critérios distintos de inclusão, não tendo por objetivo caracterizar a flora herbáceo-arbustiva de determinada área. Além disso, nem todos contemplaram todos os hábitats e formas de vida considerados no levantamento realizado na Estação Ecológica de Assis.

As famílias que se destacam pelo número de espécies na Estação Ecológica de Assis estão entre as mais ricas em espécies nos estudos da flora geral dos cerrados no Estado de São Paulo e em alguns estudos em outras regiões (Filgueiras 2002). Porém, há alternância nas famílias mais representativas entre diferentes estratos ou fisionomias da vegetação. Segundo Filgueiras (2002) geralmente as famílias dominantes em estudos da flora herbácea são Fabaceae e Asteraceae. Tannus \& Assis (2004) encontraram Bignoniaceae, Euphorbiaceae e Myrtaceae como famílias mais ricas em número de espécies no campo sujo e Cyperaceae e Poaceae em campo úmido. Em fisionomia de cerrado sensu stricto, em Santa Rita do Passa Quatro, Fabaceae e Asteraceae foram as famílias mais numerosas (Batalha \& Mantovani 2001) e, em Bauru, a família Rubiaceae foi a mais numerosa (Christianini \& Cavassan 1998). Numa vereda em Uberlândia, MG, as famílias com mais espécies foram Poaceae, Asteraceae, Cyperaceae e Melastomataceae (Araújo et al. 2002).

Na Estação Ecológica de Assis, onze famílias, que ocorreram apenas no campo úmido, foram representadas por apenas uma espécie. Estas espécies correspondem a $25 \%$ da riqueza desta fisionomia. Famílias como Apiaceae, Acanthaceae, Begoniaceae, Droseraceae e Mayacaceae são geralmente restritas a ambientes mais úmidos, como campos e brejos, sendo assim mais sensíveis a processos de antropização. Segundo Araújo et al. (2002) e Guimarães et al. (2002), áreas como campos úmidos, veredas e brejos merecem maiores esforços de preservação, pois sua riqueza florística pode ser muito facilmente perdida.

Os gêneros com maior número de espécies (Mimosa, Eugenia, Vernonia e Chamaecrista) são muito diversificados e comuns nas fisionomias mais abertas de cerrado (Filgueiras 2002). Outros estudos têm mostrado os gêneros Byrsonima e Eugenia (Weiser \& Godoy 2001) e Vernonia e Chamaecrista (Batalha \& Mantovani 2001) como os mais comuns em áreas de cerrado sensu stricto, Eupatorium, Rhynchospora e Hyptis em veredas e locais úmidos (Araújo et al. 2002) e Vernonia, Eupatorium, Rhynchospora e Utricularia em campo sujo e campo úmido (Tannus \& Assis 2004).

Geralmente a vegetação de cerrado sensu stricto tende a apresentar maior número de espécies herbáceas (Filgueiras 2002), em comparação com outras fisionomias de cerrado. Resultados semelhantes aos do presente estudo foram obtidos por Felfili et al. (1994), que também encontraram maior número de espécies para a fisionomia cerrado sensu stricto, seguido do cerradão e da mata ciliar.

Dentre todas as espécies que tiveram ocorrência exclusiva na Estação Ecológica de Assis, na comparação com as outras áreas analisadas no Estado de São Paulo, destacam-se as do gênero Piper e as formas de vida herbácea e trepadeira, que perfizeram as maiores porcentagens de espécies exclusivas. Em alguns casos, há aparente especificidade por hábitat no local do estudo. As espécies de Piper ocorreram apenas nas matas ciliares. No campo úmido, as ervas representaram $97 \%$ das espécies exclusivas deste hábitat, destacando-se Echinodorus longipetalus, Leiotrix flavescens, Rodriguezia decora, Tibouchina cerastifolia e Xyris tenella. As trepadeiras exclusivas da área de estudo pertenciam a famílias como Apocynaceae, Bignoniaceae, Convolvulaceae e Menispermaceae, sendo que a maior parte das espécies (78\%) ocorreu nas formações florestais (cerradão e mata ciliar). Uma vez que trepadeiras não foram amostradas na maioria das áreas utilizadas para comparação, é importante destacar apenas que, na Estação Ecológica de Assis, esta forma de vida está associada aos tipos florestais, que tendem a aumentar progressivamente em áreas de Cerrado protegidas contra o fogo e outras formas de perturbação (Durigan et al. 1987, Durigan \& Ratter 2006).

A riqueza de espécies fanerógamas não-arbóreas na Estação Ecológica de Assis é relativamente alta, embora seja inferior à observada em algumas das áreas comparadas, contendo vegetação de cerrado no Estado de São Paulo. No entanto, a riqueza florística do estrato arbóreo desta Unidade de Conservação é a mais alta já registrada no Brasil, tomando-se por base as 376 áreas de cerrado analisadas por Ratter et al. (2003). A predominância absoluta da fisionomia cerradão e o constante adensamento da vegetação de cerrado na região 
(Durigan et al. 1987, Durigan \& Ratter 2006) podem explicar a riqueza proporcionalmente maior da flora arbórea. Também a esse adensamento pode ser atribuído o gradual desaparecimento de espécies heliófitas de pequeno porte. Das espécies não-arbóreas listadas por Durigan et al. (1999), com dados de coletas iniciadas em 1986, 97 não foram encontradas em campo durante as expedições de coleta do presente estudo. Essas espécies, em sua maioria, podem estar se tornando mais raras na área, ou restritas a pequenos trechos não percorridos durante o inventário para este estudo. No entanto, não se pode descartar a hipótese de que estejam ocorrendo extinções locais, decorrentes do desaparecimento gradual das fisionomias abertas de cerrado, ambientes apropriados para a ocorrência de espécies heliófitas de pequeno porte.

Geralmente as plantas do componente herbáceo são mais sensíveis a pequenos distúrbios do que as árvores do cerrado (Filgueiras 2002). Mudanças na composição de espécies podem ocorrer, principalmente envolvendo espécies raras, representadas por poucos indivíduos que podem ter desaparecido em decorrência de alterações no hábitat. Felfili et al. (2000) demonstraram que, apesar de pequenas, mudanças ocorreram na composição florística de uma área de cerrado sensu stricto em um período de nove anos.

Comparações entre coletas botânicas realizadas em uma mesma área, em tempos e localidades diferentes, podem indicar mudanças na composição florística, bem como produzir resultados que se complementam e são capazes de ampliar o conhecimento da flora, mesmo em regiões consideradas relativamente bem conhecidas.

Das 301 espécies ocorrentes na Estação Ecológica de Assis, 45 (15\%) não aparecem na lista de espécies vegetais dos cerrados do Brasil (Mendonça et al. 1998). Este número de espécies exclusivas é o mais elevado entre as áreas de cerrado do Estado de São Paulo utilizadas para comparação. Batalha \& Mantovani (2001) apontaram, para o cerrado da ARIE Pé-de-Gigante, apenas 16 espécies não ocorrentes naquela lista.

Todas as áreas submetidas à análise de similaridade neste estudo encontram-se na grande região fitogeográfica denominada "Cerrados do Sudeste" por Ratter et al. (2003), com base em espécies arbóreas de todo o Brasil. Todavia, considerando-se que $25 \%$ é o limite mínimo para duas áreas serem consideradas floristicamente semelhantes pelo índice de Jaccard (Müller-Dombois \& Ellenberg 1974), com exceção de Emas, Moji-Guaçu e Santa Rita do Passa Quatro, que se assemelham, os resultados apresentados no dendrograma (figura 3) indicam que, de modo geral, as áreas de cerrado são floristicamente distintas para a flora não-arbórea, mesmo dentro de um padrão fitogeográfico único para o estrato arbóreo. Essa constatação já havia sido feita por Felfili \& Silva Júnior (1993) e Felfili et al. (2004).

De modo geral, as relações de similaridade florística observadas entre as áreas para plantas não-arbóreas não acompanham as relações observadas por Durigan et al. (2003) para o estrato arbóreo. Esses autores encontraram dois grandes grupos distintos, um formado pelas áreas de cerradão do oeste do Estado de São Paulo e outro formado pelas áreas com fisionomias mais abertas, geralmente localizadas na face leste do estado. Embora as três áreas que se agrupam na figura 3 estejam na face leste, o agrupamento esperado para a face oeste não se confirma. A baixa similaridade entre fragmentos de cerrado dispersos pelo estado configura uma elevada diversidade gama para a flora não-arbórea da vegetação de cerrado.

Almeida et al. (2005) constataram a pouca repetição de espécies de Asteraceae entre localidades, sugerindo que os remanescentes do cerrado paulista são áreas isoladas, frágeis e com alta proporção de espécies exclusivas. O tamanho reduzido de muitos desses remanescentes sugere também que muitas das espécies raras tenham populações pequenas, de baixa viabilidade em longo prazo, e com reduzida oportunidade de fluxo genético ou recolonização a partir de outras áreas.

As grandes diferenças florísticas encontradas podem, por outro lado, ser explicadas por inventários insuficientes, incapazes de detectar toda a riqueza florística dessas formas de vida com os métodos que vêm sendo utilizados. De uma ou de outra forma, esforços precisam ser direcionados à intensificação de inventários florísticos para formas de vida não-arbóreas e estratégias de conservação devem dar alta relevância a essas espécies, que podem estar muito mais seriamente ameaçadas do que as árvores, seja pela possível distribuição endêmica, pela extinção de habitat ou pelas transformações ecológicas esperadas diante de um cenário iminente de mudanças climáticas globais.

Agradecimentos - Os autores agradecem a Elisângela Pessine, Juliana Paulino e Rafael Taminato pelo auxílio nas coletas em campo; a Geraldo A.D.C. Franco e a João Aurélio Pastore (Instituto Florestal), pelo auxílio na identificação das espécies amostradas; a Eduardo da Silva Pinheiro pela confecção do mapa com as áreas de estudo; a Gabriel H. Rua (Embrapa - Cenargen) pelo auxílio na identificação das espécies de Poaceae e Cyperaceae e aos funcionários dos herbários SPSF (Instituto Florestal) e CEN (Embrapa Cenargen) pelo apoio prestado. 


\section{Referências bibliográficas}

ALMEIDA, A.M., FONSECA, C.R., PRADO, P.I., ALMEIDA-NETO, M., DINIZ, S., KUBOTA, U., BRAUN, M.R., RAIMUNDO, R.L.G., ANJOS, L.A., MENDONÇA, T.G., FUTADA, S.M. \& LEWINSOHN, T.M. 2005. Diversidade e ocorrência de Asteraceae em cerrados de São Paulo. Biota Neotropica v.5, http:// www.biotaneotropica.org.br/v $5 \mathrm{n} 2 / \mathrm{pt} / \mathrm{fullpaper?}$ bn00105022005+pt. (acesso em 15/08/2006).

ARAUJO, A.R.B., TEIXEIRA, M.I.J.G. \& RODRIGUES, R.R. 1999. Florística e fitossociologia de um trecho de cerrado no município de Franca. Naturalia 24:153-170.

ARAUJO, G.M., BARBOSA, A.A.A., ARANTES, A.A. \& AMARAL, A.F. 2002. Composição florística de veredas no Município de Uberlândia, MG. Revista Brasileira de Botânica 25:475-493.

BATALHA, M.A. \& MANTOVANI, W. 2001. Floristic composition of the Cerrado in the Pé-de-Gigante Reserve (Santa Rita do Passa Quatro, Southeastern Brazil). Acta Botanica Brasilica 15:289-304.

BATALHA, M.A., ARAGAKI, S. \& MANTOVANI, W. 1997. Florística do Cerrado de Emas (Pirassununga, SP). Boletim de Botânica da Universidade de São Paulo 16:49-64.

BRANDO, P.M. \& DURIGAN, G. 2004. Changes in cerrado vegetation after disturbance by frost (São Paulo State, Brazil). Plant Ecology 175:205-215.

CASTRO, A.A.J.F., MARTINS, F.R., TAMASHIRO, J.Y. \& SHEPHERD, G.J. 1999. How rich is flora of Brazilian Cerrado? Annals of Missouri Botanical Garden 86:192224.

CHRISTIANINI, S.R. \& CAVASSAN, O. 1998. O estrato herbáceo-subarbustivo de um fragmento de cerradão em Bauru - SP. Salusvita 17:9-16.

CORAL, D.J, PASCHOAL, M.E.S., SODRE, C. \& CAVASSAN, O. 1990. Levantamento florístico do estrato arbustivo em uma área de vegetação nativa na região de Agudos - SP. Salusvita 10:01-18.

DURIGAN, G. \& RATTER, J.A. 2006. Successional changes in cerrado and cerrado/forest ecotonal vegetation in western São Paulo State, Brazil, 1962-2000. Edinburgh Journal of Botany 63:119-130.

DURIGAN, G., SARAIVA, I.R., GARRIDO, L.M.A.G., GARRIDO, M.A. \& PECHE FILHO, A. 1987. Fitossociologia e evolução da densidade da vegetação do cerrado, Assis, SP. Boletim Técnico do Instituto Florestal 41:59-78

DURIGAN, G., BACIC, M.C., FRANCO, G.A.D.C., \& SIQUEIRA, M.F. 1999. Inventário florístico do cerrado na Estação Ecológica de Assis, SP. Hoehnea 26:149-172.

DURIGAN, G., NISHIKAWA, D.L.L., ROCHA, E., SILVEIRA, E.R., PULITANO, F.M., REGALADO, L.B., CARVALHAES, M.A., PARANAGUA, P.A. \& RANIERI, V.E.L. 2002. Caracterização de dois estratos da vegetação de cerrado no município de Brotas, SP, Brasil. Acta Botanica Brasilica 16:251-262.
DURIGAN, G., SIQUEIRA, M.F., FRANCO, G.A.D.C., BRIDGEWATER, S. \& RATTER, J.A. 2003. The vegetation priority areas for cerrado conservation in São Paulo State, Brazil. Edinburgh Journal of Botany 60:217-241.

DURIGAN, G., BAITELLO, J.B., FRANCO, G.A.D.C. \& SIQUEIRA, M.F. 2004. Plantas do cerrado paulista: Imagens de uma paisagem ameaçada. Editora Páginas \& Letras, São Paulo.

EMPRESA BRASILEIRA DE PESQUISA AGROPECUÁRIA - EMBRAPA. 1999. Sistema Brasileiro de classificação de solos. Brasília, Embrapa, Centro Nacional de Pesquisa de Solos. Serviço de Produção de Informação, Embrapa Solos, Rio de Janeiro.

FELFILI, J.M. \& SILVA JÚNIOR, M.C. 1993. A comparative study of cerrado (sensu stricto) vegetation in central Brazil. Journal of Tropical Ecology 9:277-289.

FELFILI, J.M., FILGUEIRAS, T.S., HARIDASAN, M. \& SILVA JUNIOR., M.C. 1994. Projeto biogeografia do bioma Cerrado: Vegetação e solos. Caderno de Geociências do IBGE 12:75-166.

FELFILI, J.M., REZENDE, A.V., SILVA-JUNIOR, M.C. \& SILVA, M.A. 2000. Changes in the floristic composition of cerrado sensu strictu in Brazil over a nine-year period. Journal of Tropical Ecology 16:579-590.

FELFILI, J.M, SILVA-JUNIOR, M.C., SEVILHA, A.C., FAGG, C.W., WALTER, B.M.T., NOGUEIRA, P.E. \& REZENDE, A.V. 2004. Diversity, floristic and structural patterns of cerrado vegetation in Central Brazil. Plant Ecology 175:37-46.

FIDALGO, O. \& BONONI, V.L.R. 1984. Manual prático de coleta, herborização e preservação. Instituto de Botânica do Estado de São Paulo, São Paulo.

FILGUEIRAS, T.S. 2002. Herbaceous plant communities. In The cerrados of Brazil. (P.S. Oliveira \& R.J. Marquis, eds.) Columbia University Press, New York.

GUIMARAES, A.J.M, ARAUJO, G.M. \& CORREA, G.F. 2002. Estrutura fitossociológica em área natural e antropizada de uma vereda em Uberlândia, MG. Acta Botanica Brasilica 16:317-329.

JUHÁSZ, C.E.P., CURSI, P.R., COOPER, M., OLIVEIRA, T.C. \& RODRIGUES, R.R. 2006. Dinâmica físicohídrica de uma topossequiência de solos sob savana florestada (cerradão) em Assis, SP. Revista Brasileira de Ciência do Solo 30:401-412.

MANTOVANI, W. \& MARTINS, F.R. 1993. Florística do cerrado da Reserva Biológica de Moji Guaçu, SP. Acta Botanica Brasilica 7:33-60.

MENDONÇA, R.C., FELFILI, J.M., WALTER, B.M.T., SILVA JÚNIOR, M.C. da, REZENDE, A.V., FILGUEIRAS, T.S. \& NOGUEIRA, P.E. 1998. Flora vascular do Cerrado. In Cerrado ambiente e flora. (S.M. Sano \& S.P. Almeida, eds.) Embrapa-CPAC, Planaltina.

MULLER-DOMBOIS, D. \& ELLENBERG, H. 1974. Aims and methods in vegetation ecology. John Wiley \& Sons, New York. 
RATTER, J.A., RIBEIRO, J.F. \& BRIDGEWATER, S. 1997. The Brazilian cerrado and threats to its biodiversity. Annals of Botany 80:223-230.

RATTER, J.A., BRIDGEWATER, S. \& RIBEIRO, J.F. 2003. Analysis of the floristic composition of the Brazilian Cerrado vegetation III: comparision of the woody vegetation of 376 areas. Edinburgh Journal of Botany 60:57-109.

RIBEIRO, J.F. \& WALTER, B.M.T. 1998 Fitofisionomias do Bioma Cerrado. In Cerrado: ambiente e flora (S.M. Sano \& S.P. Almeida, eds.) Embrapa/CPAC, Brasília, p.89-166.

SÃO PAULO, Secretaria de Estado do Meio Ambiente. 1997. Bases para a conservação e uso sustentável das áreas de cerrado do Estado de São Paulo. São Paulo. (Série Probio/SP).

SÃO PAULO, Secretaria do Meio Ambiente. 2005. Inventário florestal da vegetação natural do Estado de São Paulo. São Paulo: Instituto Florestal, Biota/Fapesp. Atlas.

TANNUS, J.L.S. \& ASSIS, M.A.A. 2004. Composição de espécies vasculares de campo sujo e campo úmido em área de cerrado, Itirapina - SP, Brasil. Revista Brasileira de Botânica 27:489-509.

THE ANGIOSPERM PHYLOGENY GROUP (APG). 2003. An update of the angiosperm phylogeny group classification for the orders and families of flowering plants: APG II. Botanical Journal of Linnean Society 141:399-436.
TEIXEIRA, M.I.J.G., ARAUJO, A.R.B., VALERI, S.V. \& RODRIGUES, R.R. 2004. Florística e fitossociologia de área de cerrado s.s. no município de Patrocínio Paulista, nordeste do Estado de São Paulo. Bragantia 63:1-11.

WALTER, B.M.T. 2006. Fitofisionomias do bioma Cerrado: síntese terminológica e relações florísticas. Tese de doutorado, Universidade de Brasília, Brasília.

WANDERLEY, M.G.L., SHEPERD, G.J. \& GIULIETTI, A.M. (Coord.). 2001. Flora Fanerogâmica do Estado de São Paulo. FAPESP-HUCITEC, São Paulo, v.1.

WANDERLEY, M.G.L., SHEPERD, G.J. \& GIULIETTI, A.M. (Coord.). 2002. Flora Fanerogâmica do Estado de São Paulo. FAPESP-HUCITEC, São Paulo, v.2.

WANDERLEY, M.G.L., SHEPERD, G.J., GIULIETTI, A.M. \& MELHEM., T.S (Coord.). 2003. Flora Fanerogâmica do Estado de São Paulo. FAPESP-RIMA, São Paulo, v.3.

WANDERLEY, M.G.L., SHEPERD, G.J., GIULIETTI, A.M. \& MELHEM., T.S (Coord.). 2005. Flora Fanerogâmica do Estado de São Paulo. FAPESP-RIMA, São Paulo, v.4

WEISER, V.L. \& GODOY; S.A.P. 2001. Florística em um hectare de cerrado sensu stricto na ARIE - cerrado Péde-Gigante, Santa Rita do Passa Quatro, SP. Acta Botanica Brasilica 15:201-212. 